\title{
Aproximações do Teatro do Oprimido com a Psicologia e o Psicodrama ${ }^{1}$
}

Appoximations Among The Theatre Of The Oppressed,

Psychology And Psychodrama

Aproximaciones Del Teatro Del Oprimido

Con La Psicología Y El Psicodrama
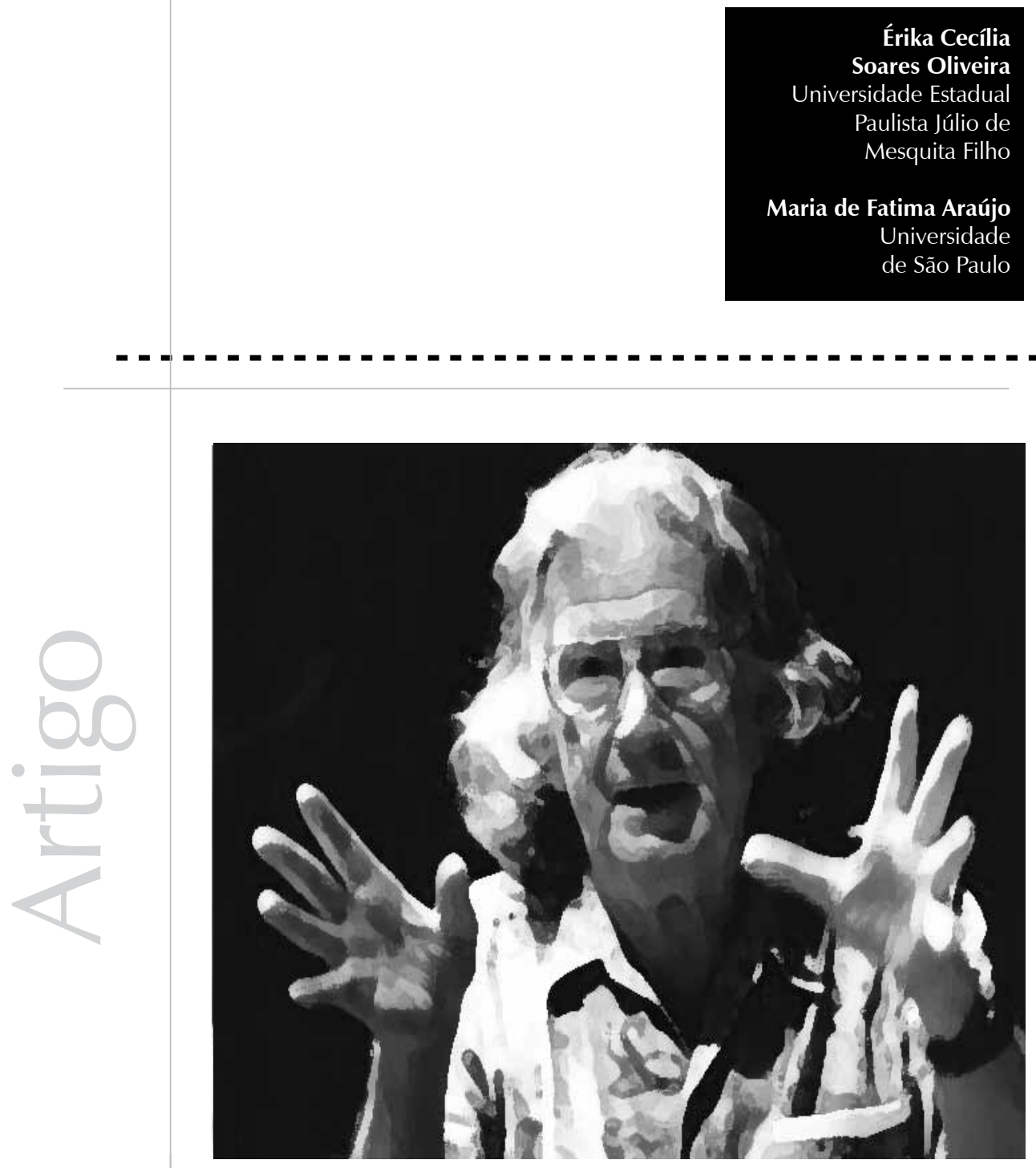
Resumo: O presente artigo aborda as aproximações do teatro do oprimido na modalidade do arco-íris do desejo, método de terapia e teatro criado por Augusto Boal com a Psicologia, em especial com o psicodrama. O teatro do oprimido é frequentemente comparado e até mesmo confundido com o psicodrama, daí a necessidade de apontarmos algumas semelhanças e diferenças entre os dois métodos, as teorias que inspiraram seus criadores, bem como os objetivos que procuravam alcançar. Procuraremos problematizar o uso das técnicas do arco-íris do desejo considerando a função e a preparação do curinga para aplicá-las, seu manejo, bem como o lugar de autoridade que lhe é conferido. As técnicas boalianas devem ser utilizadas com o devido cuidado, pois é necessário não perder de vista as possíveis consequências que o seu uso indevido pode provocar nos participantes, posto que são técnicas mobilizadoras de fortes conteúdos emocionais.

Palavras-chave: Teatroterapia. Técnicas psicoterapeuticas. Psicodrama. Psicoteatro.

Abstract: This article discusses the approaches of the theatre of the oppressed in the form of the rainbow of desire, a method of therapy and theatre created by Augusto Boal with psychology, especially with psychodrama. The theatre of the oppressed is often compared and even confused with psychodrama, hence the need to point out some similarities and differences between the two methods, the theories that inspired its creators, as well as the goals that they want to achieve. We will strive to discuss the use of rainbow of desire's techniques, considering the preparation of the joker to apply them, their management and the authority conferred on it. Boalians' techniques should be used carefully, and the applicator must not lose sight of the possible consequences such misuse may cause to their participants, since these techniques can mobilize a strong emotional content.

Keywords: Theatertherapy. Psychotherapeutic techniques. Psychodrama. Psychotheatre.

Resumen: El presente artículo aborda las aproximaciones del teatro del oprimido en la modalidad del arco iris del deseo, método de terapia y teatro creado por Augusto Boal con la Psicología, en especial con el psicodrama. El teatro del oprimido es frecuentemente comparado e incluso confundido con el psicodrama, de ahí la necesidad de que apuntemos algunas semejanzas y diferencias entre los dos métodos, las teorías que inspiraron a sus creadores, así como los objetivos que procuraban alcanzar. Procuraremos problematizar el uso de las técnicas del arco iris del deseo considerando la función y la preparación del comodín para aplicarlas, su manejo, así como el lugar de autoridad que le es conferida. Las técnicas boalianas deben ser utilizadas con el debido cuidado, pues es necesario no perder de vista las posibles consecuencias que su uso indebido puede provocar en los participantes, puesto que son técnicas movilizadoras de fuertes contenidos emocionales.

Palabras clave: Teatro del oprimido. Tecnicas psicoterapêuticas. Psicodrama. Psicoteatro.

O teatro do oprimido (TO) surgiu na década de 1970 em resposta às inquietações e experimentações de Augusto Boal, quando este ainda era diretor artístico do Teatro de Arena de São Paulo. Uma de suas preocupações era fazer um teatro para o povo e pelo povo, provocando uma revolução ao colocar os meios de produção teatral nas mãos de todos(as) e, assim, subverter o ritual convencional do teatro ao levar a plateia para o palco.

Para Boal (1980), as palavras oprimido e espectador eram sinônimas, justamente pela impossibilidade de diálogo que havia entre os(as) espectadores(as) e o palco, o que fomentava um monólogo que, por si só, era obsceno, por converter em objeto aquele(a) que se encontrava sentado(a) passivamente, atrofiando, por sua vez, sua capacidade de criar e de produzir.

Além de levar a plateia para o palco, Boal (2005) causou polêmica na classe artística com esta afirmação: - Todo mundo pode fazer teatro até mesmo os atores! Acreditando que todos os seres humanos seriam capazes de executar qualquer atividade, ele queria desconstruir a ideia do teatro como propriedade privada de poucos(as) ao demonstrar que se tratava de uma linguagem imanente a todos os seres humanos.

Para tanto, Boal introduziu duas mudanças conceituais no seu teatro. A primeira foi a passagem do(a) espectador(a) de depositário(a) passivo(a) da ação teatral para protagonista, levando-o(a) a ocupar uma posição mais 
ativa no espetáculo teatral. A segunda foi a construção de um "modelo de ação futura", que reflete não apenas o passado mas que também prepara o sujeito para o futuro (Boal, 1979).

A partir daí, Boal passa a desenvolver novas modalidades de TO, levando em conta os contextos sociais específicos, as condições de produção teatral e os objetivos a alcançar. Foi assim que surgiu o teatro jornal, no início dos anos 70, no auge da ditadura brasileira, o teatro invisivel, quando estava exilado em Buenos Aires (1971-1976), o teatro imagem, quando participava de um programa de alfabetização de adultos no Peru, o teatro legislativo, quando era vereador no Rio Janeiro, o teatro-fórum, uma das modalidades mais divulgadas e conhecidas em todo o mundo, também iniciado em um programa de alfabetização de adultos no Peru, e, por fim, o arco-íris do desejo, que surgiu nos anos 80, quando Boal vivia na França, sobre o qual nos debruçaremos neste artigo.

\section{O arco-íris do desejo: método Boal de teatro e terapia}

As técnicas prospectivas e introspectivas que compõem o arco-íris do desejo (Boal, 2002) foram elaboradas por Boal a partir das suas experiências com o TO na Europa (1978-1986). Ele observou que as opressões ali vividas eram muito diferentes daquelas encontradas na América Latina, pois não diziam respeito a problemas objetivos ou estruturais mais amplos como o desemprego, a exploração e as condições precárias de trabalho, a falta de infraestrutura, o abuso de poder e o analfabetismo. Eram problemas de natureza mais subjetiva, relacionados com a solidão, o medo do vazio e a incapacidade de se comunicar. $\mathrm{O}(\mathrm{a})$ opressor(a), segundo ele, estava dentro da cabeça das pessoas, e, para trabalhar com essas novas formas de opressão, criou o tira na cabeça (le flic dans la tête) e um conjunto de técnicas que recebeu posteriormente o nome de uma delas: arcoíris do desejo. O termo sugeria a análise de todas as cores do arco-íris, recombinandoas de acordo com o desejo das pessoas com o objetivo de ressignificar as opressões internalizadas e conferir-lhes outras feições.

O percurso teórico e prático percorrido por Boal a partir das suas experiências com o TO na Europa levou-o a uma aproximação com a Psicologia, à medida que passou a utilizar técnicas muito semelhantes às utilizadas pelos(as) psicoterapeutas. Segundo Feldhendler (2002), seu trabalho passou a se orientar muito mais para o processo do que para o produto. No final dos anos 80, o Centro de Teatro do Oprimido da França passou a oferecer seminários sobre teatro e terapia com a proposta de integrar o método terapêutico ao método de ação do TO. Nesse período, Boal chegou a admitir que seu método poderia ser considerado um psicoteatro, e que "a política era a terapia da sociedade e a terapia era a política da pessoa" (Feldhendler, 2002).

O pressuposto básico de Boal, ao juntar esses dois métodos, era mostrar o teatro como o lugar onde o sujeito poderia se ver em ação, sendo sua essência, portanto, a autoobservação. Em suas palavras: - Teatro (...) é aquela capacidade ou propriedade humana que permite que o sujeito se observe a si mesmo, em ação, em atividade (Boal, 2002, p. 27). Assim, através das técnicas do arco-íris do desejo, que condensavam as antigas técnicas do TO com as novas, criadas na década de 80 , ele acreditava ser possível tornar a atividade teatral um instrumento eficaz na compreensão e na busca de soluções para problemas interpessoais e sociais, por meio do autoconhecimento.

Para isso, defendia a ideia de que as propriedades do espaço estético auxiliavam na realização dos movimentos necessários para que a pessoa narrasse e revivesse a sua história, tornando-se protagonista e acionando 
elementos que auxiliariam na ressignificação da mesma. A plasticidade do espaço estético, uma das suas propriedades, era descrita como possibilitadora do exercício de memória e imaginação, pois permitiria a manipulação do passado, do presente e do futuro, de modo a colocar a pessoa em ação. O espaço estético seria, a um só tempo, dicotômico e dicotomizante, um espaço real dentro de outro espaço, fictício, que provocava, por sua vez, a dicotomização do próprio sujeito/protagonista e dos(as) espectadores(as). Se no palco teatral o(a) protagonista produzia pensamentos e emoções que, embora seus, pertenciam supostamente às personagens, no palco terapêutico, ele(a) reproduziria pensamentos e liberaria emoções reconhecidamente seus. Desse modo, ao reviver sua própria emoção, o desejo do(a) protagonista(a) no palco terapêutico se dicotomizaria, e ele(a) passaria a querer mostrar a cena e a mostrar-se em cena, simultaneamente. Para Boal (2002), se, ao viver o desejo na vida real, o sujeito desejava sua concreção, ao revivê-lo no palco, ele procuraria reificá-lo, transformando-o em objeto observável, passível de análise, e, talvez, de transformação. O procedimento seria terapêutico se permitisse e estimulasse a escolha de uma ou de várias alternativas para o problema apresentado.

Seria então inevitável que, ao trabalhar uma situação pessoal com as técnicas do arco-íris do desejo, em um espetáculo de teatro-fórum, por exemplo, o sujeito, com a cumplicidade da plateia, pudesse refletir e ensaiar soluções para seu conflito. Neste caso, participaria também outra propriedade descrita por Boal (2002) a respeito do espaço estético, a telemicroscopicidade, isto é, ao ampliar as ações humanas, seria possível vê-las do ângulo que se desejasse, ora aproximando-as ou afastando-as de seu(sua) observador(a). Esse espaço, por si só sensorial, faria com que o conhecimento sobre si mesmo(a) fosse adquirido através dos sentidos, sendo essa mais uma das funções terapêuticas do teatro: ver e ouvir para se autoconhecer.
Para realizar a tarefa de ajudar o(a) espectador(a) a transformar-se em protagonista da ação dramática, a fim de extrapolar para sua vida real as ações repetidas na prática teatral, Boal (2002) se valeu de três hipóteses fundamentais para amparar suas observações: a osmose, a metáxis e a indução analógica.

A osmose se caracterizaria pela propagação dos valores morais, políticos, de dominação e de poder de uma dada sociedade, infiltrados em todas as suas células, inclusive no teatro. Neste também seriam apresentadas imagens dessa vida social, com todos os elementos citados acima. Como a relação com a plateia nesse tipo de ritual era eminentemente intransitiva, a mesma era desativada, não podendo modificar o que acontecia no palco. Isso resultava em um imobilismo do ritual teatral, que, apesar de tudo, ainda poderia lançar ideias mobilizadoras, com o objetivo de fazer a plateia pensar. Boal, contudo, procurava tornar a relação palco-plateia transitiva, em uma tentativa de dinamizar a subversão dos(as) espectadores(as) e de eliminar, dessa forma, sua submissão.

Além disso, a relação intransitiva palcoplateia costumava ser produzida e sustentada através de relações de empatia (em: dentro, pathos: emoção), em que o mundo moral do espetáculo, ao penetrar de maneira osmótica no público, acabava por fazê-lo experimentar uma emoção vicária, já que se tratava de uma emoção outorgada por alguém que não a própria plateia. Em função disso, Boal sugeria a substituição da empatia, tão cara às poéticas tradicionais, pela simpatia (sym: com), na qual se vivenciaria a emoção junto ao(a) protagonista, por tê-la vivido, um dia, em sua própria vida. Paralelamente a isso, o(a) protagonista criaria imagens de sua realidade, devendo, ao mesmo tempo, jogar com a realidade dessas imagens através de sua incorporação artística, vivenciando, simultaneamente, a passagem entre dois mundos: um real e outro fictício. Esse 
pertencimento a dois mundos receberia o nome de metáxis. Uma vez criado esse mecanismo, Boal esperava que o indivíduo esquecesse o mundo real que esteve na origem da imagem criada por ele e passasse a jogar com essa nova imagem, artisticamente. Dessa forma, ele deveria efetuar uma espécie de extrapolação da realidade social e dirigirse à realidade da ficção. Depois de ter feito essa primeira extrapolação, o sujeito deveria agir em sentido inverso, isto é, em direção à realidade social.

O relato individual da opressão, proporcionado por meio de uma sessão de arco-íris do desejo, deveria, do ponto de vista de Boal, ser pluralizado, passando a abarcar a opressão de todas as pessoas da plateia, sobretudo se estas pertencessem ao mesmo grupo social e se fossem submetidas aos mesmos tipos de opressão. Se, ao contrário, aquilo que foi relatado fosse tão individual e particular que levasse a plateia a sentir apenas empatia pelo(a) protagonista, isso, por si só, faria com que este não fosse um verdadeiro representante de um espetáculo de TO. Boal preconizava que, a partir de um relato individual (ou imagem inicial), se procedesse por analogia, criando imagens ou cenas produzidas pelos(as) outros(as) participantes. Essas imagens e cenas falariam de suas próprias opressões internalizadas, similares à imagem inicial. A partir dessas imagens, e por indução, seria construído um modelo livre, isento das opressões singulares de cada um(a). A indução analógica consistiria, desse modo, em sua última hipótese fundamental na tentativa de auxiliar na extrapolação da realidade: "A função da indução analógica é a de possibilitar uma análise distanciada, oferecer várias perspectivas, multiplicar os pontos de vista possíveis por meio dos quais se pode considerar cada situação" (Boal, 2002, p. 58).

Isso resumiria a primeira necessidade do $\mathrm{TO}$, mais particularmente, do teatro-fórum, que levaria a plateia para a cena, através da multiplicação, e esta se daria por duas vias: a primeira, pela identificação, faria todos(as) se identificarem com as personagens por sofrerem a mesma opressão, levando o espetáculo a falar na primeira pessoa do plural. A analogia faria o problema de todos(as) tornar-se, de alguma forma, semelhante (Boal, 1980). A extrapolação seria a segunda necessidade técnica, pois permitira que, a partir da identificação e da analogia, as pessoas envolvidas no espetáculo (atores/ atrizes e plateia) tentassem encontrar soluções para seus problemas reais.

Cabe esclarecer que, tanto nas oficinas do arco-íris do desejo como nas demais modalidades do TO, a condução do processo é feita por um(a) curinga. O termo faz referência à carta do baralho que, por sua versatilidade, pode ocupar várias posições no jogo. $\mathrm{O}(\mathrm{a})$ curinga é um(a) multiplicador das técnicas de TO e exerce funções como coordenar a criação do texto a ser apresentado, agregar e organizar as ideias do grupo, dirigir, fazer a marcação de cena e moderar os debates dos espetáculos de teatro-fórum (Boal, 2000, 2005; Nunes, 2004; Silva, 2009).

Ao colocar em relevo os efeitos terapêuticos do teatro nas suas oficinas, Boal procurava aproximar-se das opressões mais subjetivas e internalizadas para transformá-las em algo coletivo, procurando, por meio de identificações, promover a vivência daquelas opressões como se fossem de uma só pessoa. A partir daí, produzir-se-ia uma catarse que destruiria todos os bloqueios que estariam proibindo a realização de uma ação subversiva e libertadora por parte daqueles indivíduos. Vale lembrar que a catarse preconizada por Boal é distinta das catarses aristotélica e moreniana. Na primeira, a catarse expressaria o efeito produzido pelo teatro sobre os(as) espectadores(as), causando alívio e descarga de emoções. Na catarse moreniana, o efeito terapêutico produzia-se não apenas nos(as) espectadores(as) como também nos(as) atores 
2 O psicodrama trata de um problema no qual estão envolvidos os indivíduos ou grupos pessoalmente, ao passo que, no sociodrama, os aspectos coletivos do problema são proeminentes, deixando para segundo plano a relação pessoal de cada pessoa com ele.

3Também conhecido como teatro do improviso ou teatro do imediato.

4 A conserva cultural correspondia ao produto acabado de um esforço criativo, como um livro, uma sinfonia, etc (Moreno, 1984). e atrizes que criavam o drama ao mesmo tempo em que se libertavam dele (Moreno, 1975). Desse modo, por meio da junção de técnicas terapêuticas e da arte teatral, Boal criava mecanismos de auto-observação, que permitiam ao sujeito o conhecimento de si mesmo, através da confrontação de seus conflitos.

\section{Semelhanças e diferenças entre o método de teatro e terapia de Boal e o método psicodramático de Moreno}

Antes de falarmos das semelhanças e diferenças entre os dois métodos, vamos fazer uma rápida incursão pela história do psicodrama para entender o processo de incorporação do teatro à teoria moreniana.

As primeiras aproximações de Moreno com o teatro remetem ao seu trabalho com crianças e prostitutas nas ruas de Viena, em 1921, e têm, na sua origem, uma preocupação social e política. A partir daí, ele foi aprimorando sua experiência com o teatro espontâneo que, posteriormente, deu origem ao psicodrama. No teatro da espontaneidade, Moreno (1984) apresenta um modo revolucionário de fazer teatro, diferente do que se fazia até então, por introduzir quatro mudanças radicais: a eliminação do(a) dramaturgo(a) e do texto teatral escrito, a eliminação da separação entre palco e plateia - todos(as) os(as) participantes podiam atuar como atores e atrizes, a ênfase na improvisação, tudo é improvisado: a peça, a ação, o motivo, as palavras, o encontro e a resolução dos conflitos, e a substituição do antigo palco por um palco-espaço, aberto.

Precursor do sociodrama e do psicodrama, ${ }^{2}$ o teatro da espontaneidade ${ }^{3}$ colocou as bases para o desenvolvimento da teoria e técnicas psicodramáticas voltadas para o desenvolvimento da espontaneidade e da criatividade, da ação e da atuação, do role playing e da comunicação interpessoal.

O teatro da espontaneidade de Moreno tinha como proposta levar o público ao palco, diluindo a barreira entre ambos e superando o "modo legítimo" de fazer teatro, que não levava em conta o presente, tampouco a plateia. Para ele, o "teatro legítimo" considerava apenas a "conserva cultural", ${ }^{4}$ pois levava para o palco produtos acabados do drama (cena, diálogos), na tentativa de preencher a mente dos(as) atores e atrizes, supostamente criativos(as), tornando-os(as) viciados(as) em ensaios de memória (Moreno, 1984). O palco aberto (como uma arena) permitia aos(às) espectadores(as) uma visão plena de tudo que acontecia. O(a) ator/ atriz não poderia "virar-se e fugir", pois o palco não tinha cortinas na frente ou no fundo, tampouco coxias. O aquecimento e a espontaneidade eram fundamentais para o trabalho ali realizado.

O repertório do teatro da espontaneidade era constituído por produções poéticas ou sociais. Nas palavras de Moreno: "Todas as questões concretas que excitavam o público naquele momento, os julgamentos ou debates no congresso, podem ser trazidos para o auditório do teatro e reexperenciados “(1984, p. 93).

Uma das formas de teatro da espontaneidade utilizadas por Moreno era o jornal vivo, que trabalhava com dramatizações de notícias do dia. Seu objetivo era tornar espontânea a expressão no palco, tanto em termos de forma (improviso) quanto em termos de comentário (notícias). Nele, os(as) atores e as atrizes não conheciam os argumentos que seriam encenados até o dia da apresentação, dia em que iriam se submeter ao que Moreno (1984) denominou "ato de transferência pública", ou seja, a construção de toda a poética teatral diante do público. Tudo ali obedecia à improvisação: personagens, forma e conteúdo. Para ele, a apresentação de notícias diárias permitiria o "improviso em si". 
O teatro terapêutico ou o psicodrama propriamente dito foi uma decorrência dessas incursões de Moreno pelo teatro da espontaneidade ao perceber o efeito terapêutico e catártico operado nos(as) atores e atrizes que atuavam nos espetáculos abertos ao grande público ${ }^{5}$. Surgiu como uma modalidade mais voltada para o indivíduo e para o grupo, embora não desvinculada do contexto social. Na definição do próprio Moreno (Sachs \& Moreno, 1990), o psicodrama é um método para explorar a verdade através dos métodos dramáticos, treinar a espontaneidade e desenvolver a criatividade. O material dramatizado diz respeito à realidade do(a) protagonista (paciente) - seus relacionamentos, conflitos, desejos e necessidades.

Na verdade, o que se chama de psicodrama é um conjunto de teorias e técnicas dramáticas desenvolvidas por Moreno $(1974,1975)$ ao longo da sua prática social e psicoterápica com indivíduos e grupos. Muitas dessas técnicas, bem como suas teorias, vêm sendo continuamente aprimoradas por seus(suas) seguidores(as), e seu uso não se restringe ao contexto psicoterápico, ao contrário, são vastamente utilizadas para trabalhar em diferentes contextos e temáticas - sociais, culturais, educacionais e de trabalho, dentre outros.

Há muitas semelhanças entre as práticas e as técnicas desenvolvidas por Moreno e Boal, embora nomeadas de forma diferente. Um primeiro aspecto que chama a atenção entre os dois métodos é o comprometimento de ambos com um fazer teatral revolucionário, distanciado do modelo de teatro tradicional. Embora vindo de tradições teóricas e formações diferentes - Boal era um dramaturgo marxista, Moreno era um médico mais ligado à filosofia existencialista - eles tinham preocupações comuns como a de estimular a atividade, a espontaneidade e a criatividade do(a) espectador(a) e utilizar o método dramático como método de ação para resolver conflitos e transformar a realidade social ou individual.

No entanto, em nenhuma passagem de sua obra Boal admite essas semelhanças, pelo contrário, todo o seu esforço é no sentido de diferenciar o TO do psicodrama, ainda que os considere áreas que podem ser superpostas. Ele sempre afirmou não ter experiência com o psicodrama, apesar de ter participado de um grupo de psicodrama em São Paulo, em 1967-68 e também do X Congresso da Associação Internacional de Psicoterapia de Grupo (IAGP), em 1989, que comemorou o centenário de nascimento de Moreno. A convite de Zerka Moreno, ele fez a conferência de abertura do congresso, ocasião em que apresentou as técnicas do arco-íris do desejo, mas sempre que lhe foi sugerido que Moreno (1889-1974), criador do psicodrama e da psicoterapia de grupo, poderia ter sido um precursor de seus métodos, Boal negou (Feldhendler, 2002).

Mesmo assim, quando se observam as semelhanças entre o teatro-fórum e o sociodrama, entre algumas técnicas do arcoíris do desejo e as usadas no psicodrama terapêutico, entre o jornal vivo e o teatro jornal, o playback theatre e a multiplicação dramática, pode-se inferir que Moreno e Boal tenham tido fontes de inspiração comuns ou muito parecidas, dentre elas, aspectos do teatro da espontaneidade (Aguiar, 1998) e o conhecimento que ambos tiveram das ideias, pesquisas e experiências cênicas do diretor russo Constantin Stanislavski.

Por outro lado, Boal (1980) reconhecia que aquilo que ele tornou conhecido e habitual nas suas técnicas e práticas com TO, na verdade, não foi sua criação ou de uma só pessoa, mas resultantes de manifestações estéticas surgidas e modificadas ao longo da História. Para ele, o que havia de realmente novo no TO era a ampla sistematização de todas as formas 
possíveis de expressão teatral, a investigação, a pesquisa e o aprofundamento de todos os processos, técnicas, estilos, formas, exercícios, jogos e sua inter-relação. A verdadeira descoberta do TO foi a sistematização e a inter-relação de todas elas.

O teatro audiência, por exemplo, derivado do teatro de conflito ou teatro crítico, foi um predecessor do teatro da espontaneidade. Nele, a audiência poderia interferir ativamente nas ações dos(as) atores e atrizes de modo semelhante ao que acontece no teatro-fórum de Boal. O jornal vivo, de Moreno, e o teatro jornal, de Boal, também inspirados no teatro da espontaneidade, têm como principal característica a determinação da trama pelo(a) espectador(a), o desenvolvimento e o tema da peça a partir da leitura de notícias de jornais. Por fim, a dramaturgia simultânea, utilizada por Boal no Peru e em outros países da América Latina, guardaria semelhanças com os métodos utilizados pelo playback theatre, pois ambos partiam das mesmas tradições populares de narrativas de histórias, com dois elementos fundamentais em comum: a audiência escrevia ou contava uma história e a apresentava através da ação (Feldhendler, 2002).

Para Feldhendler (2002), além das fontes de inspiração de Moreno e Boal serem parecidas, há também muitas semelhanças na abordagem de conceitos primordiais, tais como espontaneidade/criatividade, construção da cena com os(as) participantes, ação/transformação da cena/realidade, locus nascendi e espaço estético, o princípio da ação improvisada ou espontânea, a cena ou ação apresentada como espaço para mudança e, por fim, a catarse como momento de libertação.

A seguir, explicaremos alguns desses conceitos e suas semelhanças para, posteriormente, nos debruçarmos sobre as suas diferenças.
Segundo Feldhendler (2002), Boal não mencionava o termo espontaneidade, mas esta era uma condição fundamental para o seu teatro. O teatro imagem ilustra bem essa afirmação ao privilegiar explorações não verbais e cinestésicas na discussão e na elaboração das opressões vividas por seus(suas) participantes. Para ele, Boal também teria se aproximado da ideia de Moreno de "catarse de integração". Nela, o(a) protagonista descobriria que aquilo que fora entendido como uma parte reprimida ou fixada do seu caráter poderia funcionar como elemento valioso em seu repertório de papéis. Isso muito se assemelharia ao conceito de Boal de pessoa-personagem, em que sugere que podemos representar no palco aquilo que nossa pessoa moral não poderia executar na vida real. Além disso, a hipótese de Boal de que uma personalidade adoecida poderia tentar despertar personagens sadias e não reenviá-las para o esquecimento, misturandoas à personalidade, e, em consequência, permitir a ela diálogos com a saúde, também trazia muitas semelhanças com o pensamento de Moreno.

Outra aproximação refere-se ao fato de que, quando o(a) protagonista psicodramático seleciona uma situação de conflito e a reencena no aqui e agora do palco, estaria experimentando algo novo, que poderia modificar simbolicamente suas relações cotidianas. Esse caráter do como se, típico do princípio da ação improvisada ou espontânea de Moreno, seria, para Feldhendler, fundamental no teatro de Boal. Tanto para um como para o outro, o aspecto ficcional da representação da realidade permitiria uma redução dos controles cognitivos e das barreiras, ampliando as possibilidades de ação fora do palco.

Também o conceito de locus nascendi de Moreno, espaço onde ocorreria a ação teatral, teria como correspondente o espaço 
estético de Boal. Tanto Moreno como Boal trabalhavam com a perspectiva da realidade excedente, na qual as relações que ainda não ocorreram, tanto no palco como na vida, poderiam ser restabelecidas e até mesmo transformadas. Conforme Feldhendler (2002), a representação, o teste de ação e o processo de transformação ocorreriam dentro da estrutura criativa, e eram considerados pelos dois autores componentes críticos da mudança comportamental.

Por último, o autor comenta que Boal entendia a catarse psicodramática como um movimento em direção à felicidade, simplificando demais esse conceito usado por Moreno. A catarse de integração seria, do seu ponto de vista, muito semelhante à catarse sugerida por Boal, pois quando o(a) protagonista da ação é transformado(a) em ator/atriz de si mesmo(a), provoca uma experiência profunda de autoconhecimento. Esse acontecimento se daria tanto no método psicodramático como no teatro do oprimido.

Identificadas as semelhanças, abordaremos um pouco as diferenças entre os dois métodos. Para tanto, utilizaremos as reflexões do próprio Boal acerca dessas diferenças.

Em primeiro lugar, diz Boal (1980), o TO ocupa-se da primeira pessoa do plural, mesmo que o tema seja proposto por um único indivíduo. Seu objetivo é expandir-se para uma causa coletiva, daí a necessidade de se partir de uma ideia de identificação, em que os indivíduos compartilham os problemas das personagens ou então, por analogia, na qual todos(as) possuem um problema semelhante. No psicodrama, ao contrário, a tendência é ocupar-se da primeira pessoa do singular, mesmo se a resolução do problema for coletiva.

Outro aspecto que, segundo Boal, diferencia as duas práticas é que o psicodrama procura a cura através da catarse, no caso, a eliminação de um elemento inquietador. Já a catarse, no $\mathrm{TO}$, procura eliminar os bloqueios prejudiciais, que impedem o indivíduo de dinamizar e de realizar uma ação. Além disso, o TO trabalha com pessoas que se sentem saudáveis e que desejam modificar a sociedade (ou seja, não busca uma cura individual): "No psicodrama, a doença é individual; no teatro-foro, o problema é coletivo" (Boal, 1980, p. 132, grifos do autor). Assim: " (...) a medida do psicodrama é o indivíduo, a psique, a medida do TO é o coletivo, o social" (Silva, 2009, p. 121).

Além disso, ainda de acordo com Boal, no psicodrama, a figura do(a) psicoterapeuta é autoritária, pois, em última instância, ele(a) é o(a) condutor(a) de toda a situação e o(a) paciente, ao procurá-lo, busca orientações e conselhos. Já no teatro-fórum, o(a) curinga não se distingue dos(as) demais participantes, sendo, portanto, destituído de autoridade. Seu papel é reenviar as dúvidas para o grupo opinar, propor, resolver.

Na verdade, essa visão de Boal retrata seu desconhecimento da teoria e da prática psicodramáticas. Originário do teatro da espontaneidade, o psicodrama nasceu de uma preocupação social e política de Moreno de desenvolver um método de ação voltado para a transformação da realidade, através do desenvolvimento do potencial humano espontâneo e criativo. Apoiada na filosofia do encontro, conceito que por si só remete ao social e à intersubjetividade, a formulação moreniana busca compreender o socius e a psyché como uma totalidade (Bustos, 1979); o indivíduo ou o grupo são tomados sempre dentro dos contextos social, familiar, interpessoal e político. Além disso, é importante lembrar que a prática psicodramática abrange diferentes modalidades que vão do psicodrama terapêutico, voltado para o trabalho psicoterápico individual ou grupal, ao sociodrama, dirigido para questões grupais e sociais mais amplas (Moreno, 1975). 
6 Cabe esclarecer que alguns(as) autores(as) utilizam as expressões teatro do oprimido e arcoíris do desejo muitas vezes, de modo indiscriminado. Vale destacar que ambos se utilizam do relato de experiências individuais para iniciarem suas discussões, daí podermos concluir que tanto um como o outro precisam receber vários cuidados quando de sua aplicação. Neste trabalho, contudo, estamos focando apenas o uso das técnicas do arco-íris do desejo.
Da mesma forma, a afirmação de que no psicodrama o(a) terapeuta é autoritário(a) precisa ser revista. É verdade que o manejo da técnica psicodramática exige certa diretividade por parte do(a) terapeuta, mas isso é bem diferente de autoritarismo, uma vez que o(a) paciente é o(a) protagonista de todo o processo; é a partir dele(a) e em função dele(a) que o trabalho terapêutico acontece. Isso não quer dizer que não existam terapeutas autoritários(as) no psicodrama ou em qualquer outra abordagem. Como se sabe, a relação terapeuta-paciente está longe de ser simétrica pelo próprio poder que o(a) terapeuta exerce (Araújo, 1995). Como lembra Lacan (1973), é uma relação entre um sujeito suposto saber e um outro que se submete a ele. Aprender a lidar e a trabalhar com isso faz parte da formação e da prática de qualquer terapeuta. No caso do psicodrama, a postura autoritária na condução do processo psicoterápico vai contra não só ao seu princípio básico - desenvolvimento da criatividade e da espontaneidade - mas também contra o legado que Moreno deixou aos(às) psicodramatistas: - Sê espontâneo! Anima-te a criar! Não tomes a minha obra como dogma, porque estarás traindo a sua essência; toma-a como um encontro, transforma-a, não a deixes morrer nas garras da conserva cultural" (Moreno como citado em Bustos, 1979).

Além disso, cabe ressaltar que o psicodrama não procura apenas, pela via da catarse, a eliminação de um elemento inquietador. Conforme nos aponta Contro (2009), o psicodrama assinala a possibilidade de relações mais criativas e espontâneas, o que levaria o sujeito ou o grupo a elaborarem novas formas de organização pessoal e coletiva, facilitando seu grau de autonomia e de desempenho de seus papéis. Para esse autor, a catarse de integração, por sua vez, é constituída por atos que aliviariam momentaneamente o(a) paciente, sensibilizando-o(a) e permitindo novos aprofundamentos, ao mesmo tempo em que possibilitaria o contato com o material recalcado e o inconsciente, além de crescimento e de autoconhecimento.

\section{Questões e problemas acerca das aproximações do arco-íris do desejo com a Psicologia e o psicodrama}

O que está em discussão aqui não é o efeito terapêutico do teatro, mesmo porque não podemos afirmar que tais efeitos possam ser encontrados em todos os tipos de fazeres teatrais. Acreditamos que, em alguns momentos, isso até possa acontecer, tenha ele fins declaradamente terapêuticos ou não, em virtude da mobilização emocional envolvida nos processos de catarse e de identificação com as personagens e as temáticas universais abordadas, mas não constitui uma regra. Ainda que nosso objetivo central, neste momento, não seja discorrer sobre os efeitos terapêuticos do teatro, acreditamos que, por ser o arco-íris do desejo um fazer teatral que se propõe trabalhar as dimensões terapêuticas da vida humana, o mesmo acaba sendo, costumeiramente, confundido com o psicodrama (Bezerra, 2000), daí a necessidade de estabelecermos os pontos comuns e os divergentes entre os dois tipos de saberes/fazeres.

Os questionamentos que fazemos a seguir estão relacionados com certas condutas observadas na aplicação de determinadas técnicas do TO, especialmente as do arcoíris do desejo, apontadas por diversos(as) autores(as) (Nunes, 1990, 2004; Bezerra, 2000; Feldhendler, 2002; Spry, 2002) ${ }^{6}$. Antes de entrarmos nessa discussão, vale lembrar que a nossa preocupação é determinada pelo nosso olhar e o lugar de onde falamos: o campo da Psicologia. A discussão nos parece importante tendo em vista as implicações éticas e técnicas envolvidas na superposição das duas áreas - teatro e terapia - e que 
7 Essa é uma das técnicas mais complexas de todo o arsenal do TO. Ela é composta por nove etapas e deve ser usada nos casos em que

o(a) protagonista não compreende aquilo que se passa com ele(a), e tem como objetivo tornar conhecido esse conteúdo que está ainda dissimulado. As etapas a serem percorridas são baseadas em improvisações, e todos(as) os(as) participantes serão acionados(as) de modo a contribuírem para que o(a) protagonista veja e ouça melhor aquilo que, em sua trama pessoal, permanece ocultado (Boal, 2002, pp. 161-169). exigem o devido cuidado tendo em vista os diferentes contextos e especificidades de cada área. Não estamos, com isso, querendo dizer que faltaria aos(às) multiplicadores(as) das técnicas do arco-íris do desejo, no Brasil e no mundo, responsabilidade diante da aplicação das mesmas. Mas acreditamos ser necessário que novos espaços de discussão sejam abertos para que essas técnicas, quando aplicadas, possam ser conduzidas levando em consideração a série inesgotável de preocupações que todos os que aplicam técnicas e procedimentos voltados para questões íntimas dos sujeitos precisam ter. Se conseguirmos chamar a atenção para esse ponto, nosso trabalho terá avançando bastante.

Feldhendler (2002), ao falar da função terapêutica do teatro, retoma a ideia de Boal a respeito da experiência sensorial provocada por ele, experiência catalisadora de autoconhecimento que, por si só, tem um efeito terapêutico. Mas lembra que essa função terapêutica não é propriamente uma terapia, pois não leva em conta as características peculiares de uma estrutura terapêutica. A base estabilizada de cooperação, na qual os papéis e relações entre os(as) participantes são claramente definidos, bem como a clareza na execução da tarefa daqueles(as) que estão envolvidos(as) (exemplo: busca de alívio para determinados sintomas) e a concordância sobre o tempo necessário para a duração do processo, dentre outras coisas, seriam os elementos que caracterizariam um setting_terapêutico.

Esses aspectos, tão caros às psicoterapias, não são levados em consideração no espaço de oficinas teatrais, pois, não é essa a preocupação nem a função dos(as) multiplicadores(as) de uma oficina para o ensino das técnicas do arco-íris do desejo. Cabe-nos então perguntar: quais as implicações de tudo isso? Como ficam os(as) integrantes de uma oficina ao exporem suas opressões individuais à coletividade? Que garantias eles(as) têm de que seus conflitos, demandas e conteúdos emocionais mobilizados durante o processo serão acolhidos e trabalhados adequadamente pelos(as) curingas condutores(as) da oficinas, se estes(as) não têm necessariamente uma formação na área da Psicologia? Convém lembrar que muitos(as) participantes das oficinas não têm experiências anteriores ou mesmo qualquer conhecimento sobre teatro ou Psicologia que Ihes permitam avaliar os riscos e os limites da sua exposição nesse tipo vivência. Um cuidado necessário sugerido por Spry seria o(a) curinga esclarecer aos(às) participantes que o contexto é de teatro, e não de terapia, que eles(as) são responsáveis por si mesmos(as) e que só devem aceitar lidar com o que estiverem preparados(as), uma vez que o que é trabalhado é coletivo e compartilhado por todos(as). Mas isso nem sempre acontece.

Bezerra (2000) chama a atenção para o alerta que Boal faz quando do uso da técnica imagem analítica ${ }^{7}$; ele prevê que o(a) multiplicador(a) leve em conta o desejo do(a) participante de integrar essa dinâmica, e a autora pergunta-se se todos(as) os(as) multiplicadores(as) conseguem levar esse alerta em consideração. Nesse mesmo texto, a autora cita um episódio ocorrido com o próprio Boal em uma oficina no Canadá. Diante da queixa de uma participante que havia mobilizado questões pessoais que não foram trabalhadas, ele disse: - Eu faço teatro, o que vocês fazem de suas vidas é problema de vocês (Dwyer como citado em Bezerra, 2000, p. 43). Para Bezerra, a reação de Boal evidencia a confusão entre as abordagens psicológica e política, entre problemas psicológicos e opressões sociais.

Na opinião da autora, o método de teatro e terapia de Boal, o arco-íris do desejo, não possui um referencial teórico-metodológico claramente definido, não faz sequer uma confrontação entre os dispositivos teatral e terapêutico. Esses dois domínios deveriam ser 
8 Cecília Boal foi casada com Augusto Boal. É atriz e psicanalista.

9 Acting-out: termo utilizado pela psicanálise para designar ações que apresentam um caráter impulsivo e que muitas vezes toma uma forma agressiva. O actingout geralmente tem a ver como a marca da emergência do recalcado (Laplanche \& Pontalis, 1998). discutidos de forma mais rigorosa, tendo em vista melhor uso e adequação das técnicas. Da mesma forma, a função do(a) curinga nessa modalidade de TO também deveria ser problematizada, devido ao lugar de poder e responsabilidade que ocupa no processo.

Refletindo sobre a função do(a) curinga nessa prática específica, Nunes (1990), questiona se o TO pode, de fato, ser feito por qualquer pessoa, como diz Boal. Ela acredita que, assim como as técnicas psicoterápicas, as técnicas do TO também são produtoras de insights nas pessoas, e, como tal, exigem um manejo cuidadoso por parte do(a) curinga. Com relação à questão da autoridade, ela também assinala que, se o(a) curinga é um(a) facilitador(a) da liberação das opressões e da busca da verdade dos(as) integrantes do grupo, em hipótese alguma pode arrogar-se como o(a) dono(a) da verdade, como às vezes acaba acontecendo.

Outras preocupações dizem respeito às experiências vivenciadas pelos grupos nos espaços das oficinas que são, para Bezerra, "espaços abertos para autênticas dilacerações" (2000, p. 42). Nunes (1990) afirma que esse tipo de oficina pode "balançar certas estruturas" e, uma vez balançadas, o(a) participante talvez devesse procurar uma análise, fazer outras oficinas, não fazer nada ou suicidar-se. Ao que nos parece, essa última ocorrência parece pouco provável de acontecer, exceto se o manejo da oficina se der de modo abusivo. De qualquer forma, por se tratar de um campo que lida com estruturas internas, não é possível fazer nenhum tipo de controle ou de predição em torno dele, daí a necessidade de se preocupar com o manejo das técnicas, com o papel exercido pelo(a) curinga e com a duração das oficinas. No entanto, se concordamos com Nunes (1990) que o desfecho das oficinas pode se direcionar através das diversas maneiras que mencionamos acima, há que se dar atenção especial a esse tipo de experiência. Se as estruturas do sujeito forem tão invadidas a ponto de ele precisar procurar, solitariamente, respostas para o seu sofrimento, estaríamos diante de um impasse. Se, como as sessões de uma psicoterapia, as oficinas não possuem continuidade, pois esse não é seu objetivo, caberia perguntar-nos quais as limitações dessa prática e como poderíamos contorná-las caso optássemos por aplicálas. Ainda sobre isso, Cecília Boal ${ }^{8}$ (2010), ao relatar uma experiência com pacientes psicóticos(as) em Eaurbonne, localizada próxima de Paris, esclarece que o teatro possui dois elementos de contenção que funcionam como barreiras para o gozo ilimitado; seriam eles: o convite para o ato (não para o actingout ${ }^{9}$ ) e a convivência com o grupo. Ambos permitiriam a manifestação coletiva do desejo. De modo bastante esclarecedor, ela diz a respeito das experiências específicas do uso do TO em instituições de Saúde Mental: Posto que é função do diretor teatral dirigir, o que será que acontece quando o diretor se ausenta, quando o ateliê acaba e os atores se encontram novamente entregues aos seus próprios fantasmas? (Boal, 2010, p. 9). Ela conclui esse questionamento ponderando que o trabalho teatral que acontece dentro dessas instituições, por exemplo, não pode ser realizado sem a existência de uma equipe, mas deve ter continuidade e levar em consideração as especificidades de seus(suas) pacientes.

Além disso, nem sempre o tempo dedicado ao aprofundamento dessas práticas é conveniente, e seus desfechos podem ser precipitados. A proposta dessas oficinas, tendo em vista a natureza do processo, deveria, segundo Bezerra (2000), demandar maior elaboração e reflexão.

Para Nunes (1990), é preciso rever as "oficinas de informação" e as "oficinas de formação". As primeiras costumam ocorrer em curtos espaços de tempo e, nelas, os(as) participantes se entregam a exercícios "envolventes e reveladores de si", sem que 
10 Caso relatado por Boal (2002) quando de suas incursões com o Arena pelas regiões Norte e Nordeste do País. Desejoso de apresentar um teatro político para o povo, o grupo, através de suas peças, incitava a população oprimida a pegar em armas e a derramar o sangue em prol de um mundo mais justo. Em uma dessas apresentações, em um vilarejo do Nordeste, com uma plateia composta apenas por camponeses(as), surgiu Virgílio, um camponês que, comovido com o espetáculo, convida o grupo para pegar em armas junto

com eles, ajudando em sua luta. Diz

Boal (2002, p. 18): - O medo fez-se pânico, porque era difícil explicar tanto para Virgílio como para nós mesmos - como é que estávamos sendo sinceros e verdadeiros empunhando fuzis que não disparavam, nós, artistas, que não sabíamos atirar. A partir daquele momento, Boal (2002) deixa de fazer o agit-prop, isto é, o teatro de agitação e propaganda, que exortava as pessoas a lutar sem, contudo, requisitar a participação direta dos artistas nessa luta. haja, todavia, uma garantia de continuidade e de acompanhamento posterior. Nas "oficinas de formação", cujo objetivo é a apresentação didática e a prática das técnicas, o(a) participante também é convidado(a) a se envolver em exercícios e jogos, mas o que se procura ali é aprofundar a explicação a respeito da técnica, e não das respostas que o(a) participante deu aos exercícios. Ela pondera: - Podemos, mais uma vez, como na época do camponês Virgílio ${ }^{10}$, estar expondo as pessoas, sem estarmos correndo os mesmos riscos (Nunes, 1990, p. 98). Cabe a nós perguntar se Boal e, atualmente, seus(suas) multiplicadores(as). acreditam que, ao acionarmos conteúdos internos e pessoais, podemos, com o mesmo despojamento, dirigi-los, voluntariamente, para propósitos mais amplos (como, por exemplo, levá-los para um fórum, transformar a sociedade), sem que venhamos, com isso, reativar nossos sofrimentos.

As críticas acima referidas não têm como objetivo desconsiderar a contribuição do arco-íris do desejo na emancipação das pessoas ou no efeito terapêutico que possa ter, mas sim, chamar a atenção para os problemas decorrentes de determinadas condutas no manejo das técnicas e na condução do processo por parte dos(as) curingas, especialmente na formação dos(as) multiplicadores(as) do TO. Como assinala Bezerra, o uso inadvertido dessas técnicas pode afastar o TO das suas raízes contestatórias. E mais, se aplicadas sem aprofundamento ou embasamento teórico, poderão produzir novas opressões nas pessoas, agora praticadas por aqueles(as) que justamente desejam combatê-las.

\section{Considerações finais}

Boal criou as técnicas do arco-íris do desejo pensando, a partir de uma situação pessoal, em permitir que o sujeito encontrasse alternativas para o problema apresentado, acreditando que esse seria um dos efeitos terapêuticos de seu método. Para ele, o espaço estético, sensorial por si só, permitiria que o sujeito adquirisse autoconhecimento, e essa seria outra função terapêutica de sua técnica. Para tanto, ele criou algumas hipóteses que permitiriam que, a partir da história particular desse sujeito, todas as pessoas pudessem procurar uma solução, uma vez identificadas com a opressão que estava sendo narrada, passando o espetáculo a falar na primeira pessoal do plural. Ele esperava, com isso, que o sujeito que narrou a história esquecesse o mundo real que esteve na origem da imagem criada por ele e passasse a jogar com essa nova imagem, mas agora artisticamente. Isso realizado, haveria uma extrapolação da realidade social em direção a outra realidade, fictícia. Feita essa primeira extrapolação, o sujeito deveria agir em sentido inverso, voltando à direção da realidade social. Desse modo, através da junção de técnicas terapêuticas e da arte teatral, Boal criava mecanismos de auto-observação e de extrapolação da realidade, entendendo que, a partir do autoconhecimento, seria possível estender o conhecimento para problemas mais amplos e coletivos.

Essa nova forma de lidar com as opressões, criada a partir da observação da realidade europeia, muitas vezes foi confundida e comparada com o psicodrama. Neste artigo, pudemos perceber que tanto Moreno como Boal possuíam alguns pressupostos parecidos, como o desejo de que a plateia interagisse com os(as) atores e atrizes, a procura pela espontaneidade e a liberação dos conflitos pessoais e sociais, dentre outros. Cabe ressaltar que ambos, cada qual a seu modo, estiveram comprometidos com um fazer teatral que revolucionava e se distanciava do modo tradicional de se fazer teatro, além de utilizarem o método dramático como método de ação para a resolução de conflitos e a transformação da realidade social e individual, preocupados que estavam com as questões políticas e sociais de sua época. 
De forma geral, as técnicas usadas para as discussões do teatro do oprimido também partem de questões do próprio sujeito, mas é a partir das técnicas do arco-íris do desejo que Boal tenta dar uma dimensão terapêutica para a sua prática, aí se debruçando sobre os conflitos mais íntimos do sujeito. Essa prática foi problematizada neste artigo a fim de que possamos apenas levantar alguns apontamentos, como, por exemplo, a função do(a) curinga e do manejo que ele(a) dá às técnicas do arco-íris, a transferência de poder que é endereçado a ele(a), a duração e o aprofundamento das oficinas; enfim, ainda que não se trate de um setting_terapêutico, pensamos que seja necessário dar um tratamento diferencial quando do uso desse tipo de abordagem, por estarmos lidando com pessoas suscetíveis de se expor de maneira indesejada. Evidentemente, não temos respostas para todas essas questões, mas como há poucas publicações nessa área, esperamos, com este texto, abrir um espaço de diálogo e discussão sobre uma prática que vem ganhando cada vez mais adeptos(as), inclusive dentro do campo da Psicologia, não sem razão, pois o método criado por Boal permite que tenhamos uma escuta privilegiada diante daquelas pessoas emudecidas pela diferentes formas de opressão da nossa sociedade, permitindo-lhes que tenham acesso a meios de comunicação mais coletivos. 


\section{Érika Cecília Soares Oliveira}

Doutoranda do programa de pós-graduação em Psicologia e Sociedade pela Universidade Estadual Paulista Júlio de Mesquista Filho, São Paulo - SP - Brasil. Bolsista pela Fundação de Amparo à Pesquisa do Estado de São Paulo. E-mail: oliverik_br@yahoo.com.br

\section{Maria de Fatima Araújo}

Pós-doutorado em Medicina Preventiva (área Gênero e Saúde) na FM/USP. Docente no Programa de Pós-Graduação em Psicologia (UNESP/Assis). - SP - Brasil.

E-mail: fatimaraujo@uol.com.br

Endereço para envio de correspondência:

Rua Henrique Schaumann, 1180/101 Pinheiros. São Paulo, SP - Brasil. CEP: 05413-011

Recebido 20/6/2011, 1a Reformulação 5/12/2011, Aprovado 10/1/2012. 


\section{Referências}

Aguiar, M. (1998). Teatro espontâneo e psicodrama. São Paulo: Agora.

Araújo, M. F. (1995). Reflexões sobre o papel social e político do profissional de psicologia. Perfil, 8, 33-39.

Bezerra, A. P. (2000). Augusto Boal e as técnicas do arco-íris do desejo. Cadernos do JIPE-CIT, 10, 24-32.

Boal, A. (1979). Técnicas latino-americanas de teatro popular: uma revolução copernicana ao contrário (com o anexo teatro do oprimido na Europa). São Paulo: Hucitec.

Boal, A. (1980). Stop: c'est magique! Rio de Janeiro: Civilização Brasileira.

Boal, A. (2000). Hamlet e o filho do padeiro: memórias imaginadas. Rio de Janeiro: Record.

Boal, A. (2002). O arco-íris do desejo: método Boal de teatro e terapia. Rio de Janeiro: Civilização Brasileira.

Boal, A. (2005). Teatro do oprimido e outras poéticas políticas. Rio de Janeiro: Civilização Brasileira.

Boal, C. T. (2010). Teatro do oprimido em Eaubonne. In Metáxis: teatro do oprimido na Saúde Mental (pp. 6-9). Rio de Janeiro: Master Print Gráfica e Editora.

Bustos, D. M. (1979). Prólogo. In A. Naffat Neto. Psicodrama: descolonizando o imaginário (pp. 11-12). São Paulo: Brasiliense.

Contro, L. C. (2009). Grupos de apoio ao processo de trabalho em saúde: articulações teórico-práticas entre psicodrama e análise institucional. Tese de doutorado. Departamento de Medicina Preventiva e Social, Pós-Graduação em Saúde Coletiva, Universidade Estadual de Campinas, Campinas, SP.

Feldhendler, D. (2002). Augusto Boal and Jacob L. Moreno: Theatre and therapy. In M. Schutzman, \& J. Cohen-Cruz. Playing Boal: Theatre, therapy, activism (pp. 87-109). Londres: Taylor \& Francis e-Library.

Lacan, J. (1973). O seminário: livro 11. Rio de Janeiro: Zahar.

Laplanche, J., \& Pontalis, J. B. (1998). Vocabulário de psicanálise. São Paulo: Martins Fontes.
Moreno, J. L. (1974). Psicoterapia de grupo e psicodrama. São Paulo: Mestre Jou.

Moreno, J. L. (1975). Psicodrama. São Paulo: Cultrix.

Moreno, J. L. (1984). O teatro da espontaneidade. São Paulo: Summus.

Nunes, F. P. (2010). Palco ou plateia? A progressiva falta de assento nos teatros de Brecht, Moreno e Boal . Dissertação de mestrado, Instituto de Artes, Universidade de Brasília, Brasília, DF.

Nunes, S. B. (1990). Teatro do oprimido: revolução ou rebeldia? Dissertação de mestrado. Departamento de Psicologia, Pontifícia Universidade Católica do Rio de Janeiro, Rio de Janeiro.

Nunes, S. B. (2004). Boal a Bene: contaminações para um teatro meno. Tese de doutorado em Psicologia Clínica. Pontifícia Universidade Católica de São Paulo, São Paulo.

Sachs, J., \& Moreno, J. L. (2000). A voz de J. L. Moreno (Entrevista a James Sachs). Revista Brasileira de Psicodrama, 8(2), 11-27.

Silva, C. V. (2009). Curinga - uma carta fora do baralho: a relação diretor/espectador nos processos e produtos de espetáculos fórum. Dissertação de mestrado em Artes Cênicas. Universidade Federal da Bahia, Salvador, BA.

Spry, L. (2002). Structures of power: Toward a theatre of liberation. In M. Schutzman, \& J. Cohen-Cruz, Playing Boal: theatre, therapy, activism (pp. 171-184). Londres: Taylor \& Francis e-Library. 
Pedido de publicação de errata do artigo publicado no vol. 32 (2), 354

\section{Dados corretos}

Maria de Fatima Araújo

Pós-doutorado em Medicina Preventiva (área Gênero e Saúde) na FM/USP. Docente no Programa de Pós-Graduação em Psicologia (UNESP/Assis).

Pedido de publicação de errata para o texto do homenagedo Francisco Pedro Estrázulas Pereira de Souza 32 (2), 536

\section{Francisco Pedro Estrázulas Pereira de Souza}

O homenageado desta edição carrega uma característica muito importante: é o 11o psicólogo registrado no Conselho Regional de Psicologia do Rio Grande do Sul (CRP/RS). Mais conhecido como Chico Pedro, o psicólogo Francisco Pedro Estrázulas Pereira de Souza nasceu em São Gabriel (RS) no dia 7 de maio de 1927; completou 85 anos em 2012. Sua família participou de lutas históricas, entre elas, a Revolução Farroupilha, em 1835. Seu nome é uma homenagem a São Francisco de Assis, devido ao catolicismo da mãe. O pai, engenheiro sanitarista, sempre o apoiou nos estudos e prezava muito a liberdade e o pensamento crítico-construtivo. Atualmente, Chico Pedro participa de comissões no CRP/RS e da Sociedade de Psicologia do Rio Grande do Sul.

Chico Pedro se casou em 1950 com sua companheira de cursinho, Edela Lanzer, e ambos queriam entrar para a Faculdade de Filosofia da Universidade Federal do Rio Grande do Sul (UFRGS). Ele e a esposa ingressaram juntos na UFRGS, e, em 1949, obtiveram o título de Bacharel em Filosofia, e um ano depois, a Licenciatura.

As atividades coincidiam. Além de um casal de filhos psicólogos, a união gerou bons frutos. O casal trabalhava junto em três áreas clássicas das aplicações psicológicas: clínica, organizacional e escolar. O casal também se destacou pelas contribuições à Psicologia organizacional, à dinâmica de grupo e às relações humanas. Além disso, Chico Pedro colaborou como professor do Curso de Especialização em Psicologia na UFRGS.

Em 1956, ele e a esposa passaram a colaborar com a PUCRS como professores no Centro de Orientação Pedagógica para professores do ensino comercial. O trabalho repercutiu a tal ponto que o casal foi para os Estados Unidos realizar mestrado. Em 1962, Chico Pedro obteve o título de Mestre em Administração Pública.

De volta ao Brasil, o casal assumiu disciplinas de Psicologia que eram oferecidas no curso de pós-graduação em Administração Pública da UFRGS: administração de pessoal, relações humanas, laboratório de sensitividade, Psicologia organizacional e dinâmica interpessoal. Chico foi coordenador do Programa de Pós-Graduação em Administração no período 1973 a 1974. O casal permaneceu vinculado ao Programa de Administração até a aposentadoria, por volta de 1983.

O psicólogo fez parte do grupo que organizou o Primeiro Encontro Regional de Psicologia Organizacional, em 1976, com o tema Demandas atuais e fatores de expansão da Psicologia Organizacional. Chico Pedro acabou se destacando também na organização das edições seguintes do evento. Devido ao grande sucesso desses eventos regionais, em 1982, o encontro passou a ser realizado nacionalmente. O objetivo do então Encontro Nacional de Psicólogos e Administradores era aproximar profissionais e discutir as divergências entre eles. Chico acredita que o movimento social para a institucionalização da Psicologia organizacional no Brasil progrediu rapidamente.

Posteriormente, o psicólogo ajudou a fundar a Sociedade Brasileira de Dinâmica de Grupo. Essa etapa da sua vida profissional ficou marcada pela forte atuação na área de Psicologia organizacional, de trabalho e de recursos humanos.

Chico também ajudou a fundar a Sociedade de Psicologia do Rio Grande do Sul em 1952. Chico foi o primeiro representante do crp/07 eleito por voto direto para conselheiro federal. Edela foi eleita a segunda presidente do crp/07. Foi também presidente da Sociedade de Psicologia. A competência profissional de Chico e de sua esposa foi reconhecida pela Organização das Nações Unidas para a Educação, a Ciência e a Cultura (Unesco), quando foram convidados a integrar uma equipe internacional para trabalhar no projeto Os efeitos da hierarquia no comportamento dos membros da organização. 